\title{
The Essential Role of Pharmacy Leaders in Guiding Change
}

\author{
Lauza Saulnier
}

$\mathrm{I}^{\mathrm{n}}$

n February 2017, I attended the 27th annual Canadian Society of Hospital Pharmacists (CSHP) Harrison Pharmacy Management Seminar. The education program at this event offered professional development and networking opportunities for pharmacy leaders across the country, and, for me, a welcome escape in Harrison Hot Springs from the cold weather of the Maritimes.

Education topics such as implementing new technology, advancing pharmacy practice, and enhancing patient safety shared a common thread: the essential role of pharmacy leaders and managers in the success of a change initiative.

In today's environment, health care organizations are required to adopt new technologies and innovative, efficient practices, and they must be open and receptive to change. More than two decades ago, author and leadership guru John P Kotter explained the need to follow a stepwise process for leading change and described the errors that people often make with their change efforts (Harvard Bus Rev. 1995 May-June; www.gsbcolorado.org/ uploads/general/PreSessionReadingLeadingChange-John_ Kotter.pdf). Kotter's guidance continues to hold true.

Organizations will face struggles in achieving their desired outcomes-unless all individuals affected by the change go through their own change transition from current to future state. In other words, organizational change is all about engaging people!

Leaders are taught to manage processes and resources effectively. However, change requires the management of individuals' emotions and responses. The "people side" of change and transition is an aspect that most leaders find difficult to address.

Several best practice methodologies can be used to achieve change. The Prosci ADKAR model for change (www.prosci.com/ adkar/adkar-model) focuses on change at the individual level and on creating the right conditions for those affected by change to adopt new behaviours. ADKAR stands for the following principles:

- Awareness of the need for change

- Desire to support and take part in the change

- Knowledge of how to change and what to do

- Ability to implement the change on a day-to-day basis

- Reinforcement to sustain the change
Given their unique relationship with their employees, pharmacy leaders and managers are in an ideal position to communicate change, advocate for change, coach and influence employees through the change process, and manage resistance. In Best Practices in Change Management-2016 Edition (Prosci

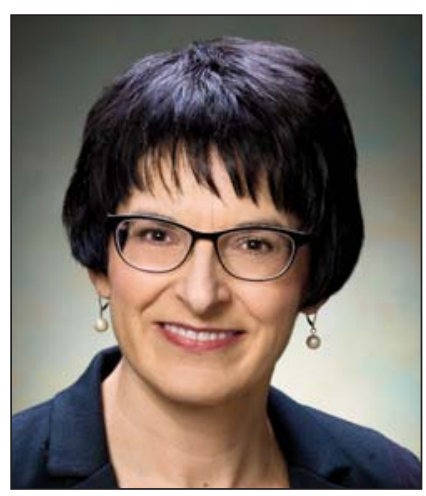

Inc, Fort Collins, Colorado), participants identified engagement with and support from managers and supervisors as top contributors to the success of change management. Although managers are recognized as a critical factor in times of change, they must first be on board with the change and must also be adequately prepared before they can support their employees.

Through CSHP, hospital pharmacists can enjoy a strong and united community of practice. Over the years, I have appreciated the value of, and have gained a better appreciation for, the "softer" benefits of my CSHP membership, through camaraderie, an enthusiastic willingness to share experiences, and the drive for excellence.

Being an active member of CSHP offers many opportunities to develop and apply leadership skills while being supported by pharmacy leaders with diverse experience in hospitals and other collaborative health care settings. Take advantage of this unique learning opportunity and help us to shape the future of hospital pharmacy practice by becoming involved in your professional organization today!

Lauza Saulnier, BSC(Pharm), ACPR, is President and Vision Liaison for the Canadian Society of Hospital Pharmacists. 